\title{
Review on micro-encapsulation with Chitosan for pharmaceuticals applications
}

\begin{abstract}
There is evidence that several systematic researches recognized the importance of using polymers in drugs manufacturing. Natural polymers are usually biocompatible, biodegradable and non-expensive like chitosan. Chitosan is one of the natural biodegradable groups of polymers that have been extensively used for microencapsulation of drugs like isoniazid, propranolol and aspirin. This natural polysaccharide has many pharmaceuticals applications, such as oral and parenteral delivery of drugs. It is important for a wide range of scientific and industrial processes to know the applications of chitosan microparticles loaded drugs in pharmaceuticals fields. Recently, this issue was the objective of many research papers in the literature. Chitosan can also be combined with other polymer to encapsulate many drugs in order to achieve targets with performance delivery. Recent advances in microencapsulation methods have facilitated investigation of chitosan usage to load drugs. This review about the preparation of chitosan-based-micro and particles by many fabrications methods of pharmaceutical applications including coacervation, drying techniques, ionic cross-linking, ionotropic gelation and emulsion solvent diffusion method.
\end{abstract}

Keywords: Polymer, emulsion, chitosan, drug delivery systems, ionotropic gelation
Volume I Issue 2 - 2018

\author{
Abdelkader Hassani, Siti Aslina Hussain, \\ Norhafizah Abdullah, Suryani Kmaruddin \\ Department of Chemical and Environmental Engineering, \\ Universiti Putra Malaysia, Malaysia
}

\begin{abstract}
Correspondence: Siti Aslina Hussain, Department of Chemical and Environmental Engineering, Faculty of Engineering, Universiti Putra Malaysia, 43300 UPM Serdang, Selangor, Malaysia, Tel 0389466292, Fax 86567I 20, Email aslina@upm.edu.my
\end{abstract}

Received: April 4, 2018 | Published: April 24, 2018

\section{Introduction}

\section{Background}

As one of the most important forms of drugs and compounds microencapsulation is disseminated in several industrial fields, particularly in pharmaceutical industry with encapsulation of proteins drugs, it offers various advantages as drug delivery system. One of the benefits of this technique is the protection of active agent in order to improve the effectiveness of medical treatment. The applications of microencapsulation augmented in many drugs form over the last two decades. Due its higher ratio of nitrogen (6.89\%), chitosan has a great economical interest as compared to other polymers like cellulose. ${ }^{1}$ Microencapsulation can also be used to increase the efficiency of many products in the industry. Moreover, it allows the formulation of many pharmaceutical products, reforming and giving them healthier and more properties as bioactive roles in the body. ${ }^{2}$ Microencapsulation provides likely advantages for standard drug delivery systems and is also recognized as unique transporter systems for many pharmaceuticals. Even though important developments have been made in the domain of microencapsulation techniques. Microencapsulation has become increasingly important in the fields of cell and pharmaceutical engineering. It helps to develop the drug formulations and oral or parenteral delivery systems. At present, there are many marketed microencapsulated products used for the delivery of pharmaceutics. ${ }^{3}$ In this review, the term microencapsulation includes microcapsules, microparticles, microspheres, and also microemulsions. The term microsphere with small particles of solid diffuse in a continuous polymer sell or matrix is used largely for a homogeneous structure, which is made by one continuous phase, in a solid matrix particle. Figure 1 shows microcapsule with core and shell (coat). The active agent is usually melted or dissolved in the same container as the active agent before accuracy article fabrication treats into microspheres. On the other hand, microcapsule contains an inner core and an outer shell. The microcapsule core can be made from liquid or solid and usually includes the active agent. The shell of a microcapsule is generally made from polymer or wax. In order to reach the adequate release kinetics of the core, many accuracy controls of shell thickness and density can take place. Microcapsule is used also with well-defined core material that contains reservoir-like structure and envelope/coat. There are many types of microcapsules that can be different in functions, compositions, and sizes. The final goal or site of microencapsulated product defines usually the type of microcapsule. The entrapment of many substances such as solids, drugs, liquids, proteins, stem and bacterial cells can be made with these small particles. With this variety of entrapment substances, microencapsulation has a large area of applications, like artificial cell, tissue delivery, and drug delivery. Another significant use of microencapsulation is microorganisms. In this area, vector systems can play an important role to deliver drugs into target cells. The accumulation of bacteria such as clostridium salmonella in tumors in vivo can make them effective for cancer gene therapy vectors. ${ }^{5}$

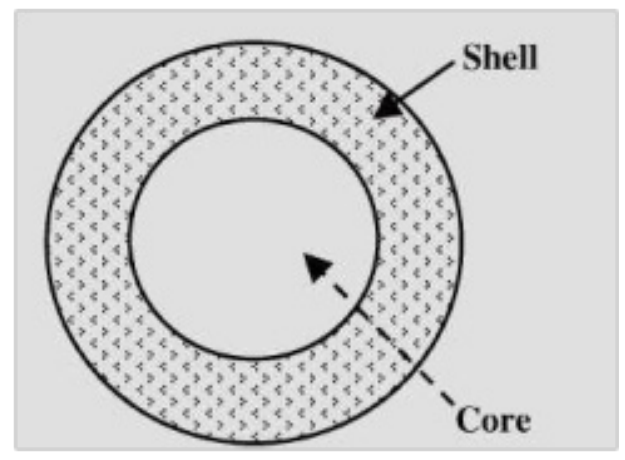

Figure I Microcapsule contained core and coat or shell. ${ }^{4}$

\section{Definition of microencapsulation}

The term capsule states a solid structure of core and shell or core material and coating material as shown in Figure 2. The word microcapsules imply the membrane surrounded particles or droplets 
distributed in solid matrix. ${ }^{6}$ Microencapsulation can be defined as the process of surrounding or enveloping a continuous phase of polymeric substance within very tiny solid or liquid particle, yielding microcapsules or microparticles which are small and are made of natural or synthetic polymers. The diameters of these flowing free particles are ranging from 1 to $1000 \mu \mathrm{m} .^{7}$ Microencapsulation makes available the processes of converting liquids to solids, and also providing environmental protection with the characteristic of control release of coated material. Majority of these characteristics can be reached by various techniques, though the distinction of microencapsulation is the small size of the covered microparticles and their following use and adoption to a wide selection of dosage samples and pharmaceutical formulations, which until now may not have been practicable technically.

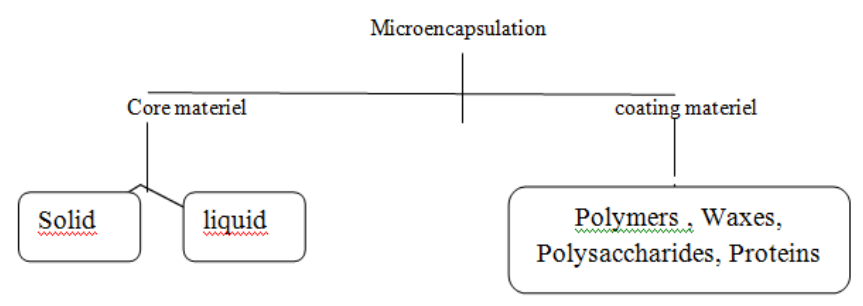

Figure 2 Fundamental consideration of microencapsulation.

\section{Chitosan properties and its usage as a pharmaceutical encapsulating agent}

Chitosan is one of the most used polymers as an encapsulate agent in pharmaceutical industry. It is a natural, biodegradable, and linear polysaccharide that consists of distributed $\beta$-(1-4)-linked N-acetylD-glucosamine (acetylated unit) and D-glucosamine (deacetylated unit). This non-toxic polymer is prepared by the treating of shrimp's chitin shells, crabs and other sea crustaceans. Figure 3 shows the process of deacetylation of chitin, which is the simple process to produce chitosan using sodium hydroxide and water. The reaction is made in two steps under high level activation energy. ${ }^{8}$ Previous research has established that chitosan presents significant properties, which can be put it in the way for the use in the pharmaceutical and biopharmaceutical research areas like vaccine technology, mucoadhesion, and permeation enhancement. However, chitosan properties, such as low solubility in water and organic solvents reduce its exploitation for special functions. The chemical modification of the chain is the best process to enhance and impart new properties to chitosan. This delicate process made usually by grafting of active groups, without variation of the original skeleton in order to save the initial characteristics. The protonation process in acid environment to neutral solution can take place due to the $\mathrm{pKa}$ value of amino group in chitosan $(\sim 6.5)$. The reaction depends on $\mathrm{pH}$ and the \%DA (The degree of deacetylation)-value. Hence, chitosan become bioadhesive and binds easily to surfaces that negatively charges like mucosal membranes. ${ }^{9}$ Due to its biodegradability and biocompatibility, chitosan improves the role of polar drugs through epithelial surfaces. Even so, the major inconvenient of chitosan is the poor solubility in water, which can limit its usage for many drugs formulations. ${ }^{10}$ This polymer is soluble in acetate buffer solutions under $\mathrm{pH}$ of $6.5 .{ }^{11}$ Moreover, the positive charge of chitosan skeleton giving rises to be more soluble in neutral and basic solutions. An increase in solubility of chitosan can be made despite of the protonation of amino group in acidic solution. The practice of this property has a great importance on biomedical applications when the chitosan is used to deliver drugs to acidic environment targets. ${ }^{12}$ With regards to its excellent filmforming ability and cationic characters, chitosan can also react with polyanions and produce polyelectrolyte complexes. In addition to that, the biological properties of this polymer have paved the way of easy usage, mostly in the fields of biomedical and pharmaceutical applications. ${ }^{13}$ It has been reported that chitosan is considered as a good candidate for wound dressing due its hemostatic properties. ${ }^{14}$ Despite of its antibacterial property, chitosan helps to restrict the risk of local infection. ${ }^{15}$ Consequently, using its intrinsic properties, chitosan has a great potential used in common applications for the preparation of microspheres/nanospheres and microcapsules in pharmaceutical field. There are many techniques used to encapsulate drugs with chitosan such as coacervation, and ionotropic gelation. ${ }^{16}$ Table 1 shows numerous biological and physicochemical properties of chitosan that influenced the usage in various applications and fields.

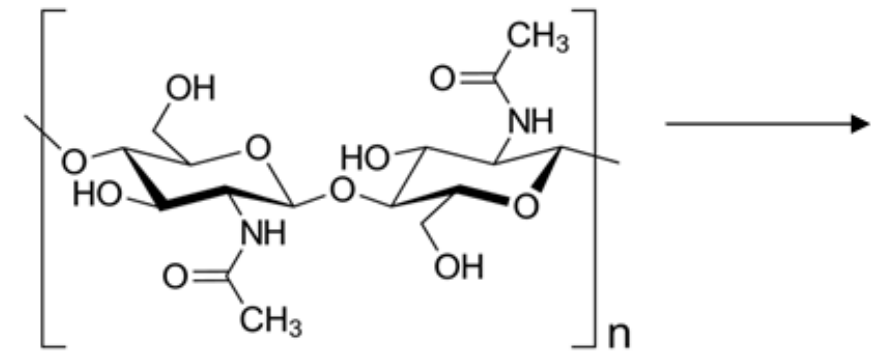

Chitin

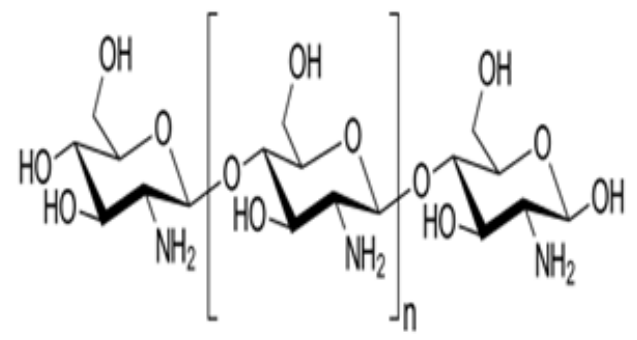

Chitosan

Figure 3 Scheme of $\mathrm{N}$-deacetylation of chitin into chitosan.'

\section{Techniques of microencapsulation process in pharmaceutical applications}

Many techniques of microencapsulation have been commonly used as a carrier of drug delivery and improved drugs. These techniques commonly result in products including numerous types of coated particles. The precise numbers of particles required to make a form of single administered dose which can vary functionally in the final particle product size and can be kept in either the microor nanometer type range for micro and nanoparticulate drug delivery 
systems respectively. Table 2 mentions various techniques that have been selected for microencapsulation. Generally they can be divided into two main basic groups, namely chemical and physical processes. Microencapsulation process has greatly improved researches of pharmaceutics in terms of drug delivery systems; thus, has increased the efficacy of therapeutics. As aforementioned, microencapsulation reduces dosage requirements and prolongs the stability of drugs. ${ }^{5}$ Table 3 mentions numerous pharmaceutical applications of many microencapsulation techniques.

Table I Physicochemical and biological properties of chitosan ${ }^{17}$

\begin{tabular}{ll}
\hline Physicochemical properties of chitosan & Biological properties of chitosan \\
\hline $\begin{array}{l}\text { Frequently prescribed for acts as an antacid } \\
\begin{array}{l}\text { Linear polyamine with reactive amino and hydroxyl } \\
\text { groups available }\end{array}\end{array}$ & $\begin{array}{l}\text { Fundamental as a biocompatible, immunoadjuvant, biodegradable natural polymer, } \\
\text { safe, and non toxic }\end{array}$ \\
Absorption and binds fat & $\begin{array}{l}\text { Binds microbial cells with antitumoral activity Has a pivotal role in the } \\
\text { regenerative circle on connective gum tissue }\end{array}$ \\
Fundamental as a spermicidal, fungistatic, hemostatic, and anticholesterimic & $\begin{array}{l}\text { Promotes weight loss and helps accelerate the formulation of osteoblast cells } \\
\text { responsible for bone formation } \\
\text { Frequently prescribed to promote wound healing and depressant on central } \\
\text { nervous system }\end{array}$ \\
Antifungal, antibacterial and reduces low-density lipoprotein (LDL) cholesterol
\end{tabular}

Table 2 Microencapsulation techniques ${ }^{18}$

\begin{tabular}{lll}
\hline Chemical process & Physical process & Physico-chemical processes \\
\hline Interfacial polymerization & Spray drying & Polymer incompatibility \\
Poly condensation & Air-suspension coating & lonotropic gelation \\
Polyelectrolyte complexation & Vibration nozzle & Sol-gel encapsulation \\
Cryogenic solvent extraction & Pan coating & Supercritical $\mathrm{Co}_{2}$ assisted microencapsulation \\
Phase separation (Coacervation) & Centrifugal extrusion & \\
Solvent evaporation and extraction & & \\
Interfacial polymerization & \\
Suspension polymerization & \\
Complex coacervation & \\
In situ polymerization & \\
Emulsion Polymerization & \\
Coacervation and phase separation & \\
Matrix polymerization & \\
Liposome technology &
\end{tabular}


Table 3 Microencapsulation techniques and examples of its pharmaceutical applications ${ }^{18}$

\begin{tabular}{|c|c|c|c|}
\hline Drug (core materials) & Applications & Coating materials & $\begin{array}{l}\text { Microencapsulation } \\
\text { techniques }\end{array}$ \\
\hline Insulin, doxorubicin & $\begin{array}{l}\text { Drug delivery system (ex: oral } \\
\text { administration of insulin) }\end{array}$ & $\begin{array}{l}\text { Poly (alkyl cyanoacrylate), } \\
\text { poly(butylcyanoacrylate) }\end{array}$ & Emulsion Polymerization \\
\hline $\begin{array}{l}\text { Amino acid, enzymes, } \\
\text { antibody }\end{array}$ & Drug delivery system & Polyamide microcapsules & Interfacial polymerization \\
\hline Chlorothiazide & Drug delivery system & Protein (Albumin), polysaccharides & Suspension crosslinking \\
\hline BSA (bovine serum albumin) & Drug delivery system & $\begin{array}{l}\text { (Polycaprolactone) and PLGA } \\
\text {-(poly(DL-lactic-co-glycolic acid) }\end{array}$ & $\begin{array}{l}\text { Solvent evaporation/ } \\
\text { extraction }\end{array}$ \\
\hline $\begin{array}{l}\text { Use gelatin and gum arabic } \\
\text { (acacia) to encapsualte } \\
\text { pentobarbituric acid }\end{array}$ & $\begin{array}{l}\text { Encapsulation of liquid, solid } \\
\text { drug particles which have the } \\
\text { ability to disperse in polymers } \\
\text { solutions }\end{array}$ & $\begin{array}{l}\text { Protein, Polysaccharides, Gelatin , Ethyl } \\
\text { cellulose, Gum arabic, Aqueous gelatin } \\
\text { solution, Gelatin-water-ethanol system, } \\
\text { cellulose acetate phthalate solution }\end{array}$ & $\begin{array}{l}\text { Coacervation/phase } \\
\text { separation }\end{array}$ \\
\hline $\begin{array}{l}\text { Diphtheria toxoid Leuprorelin } \\
\text { acetate Tetanus toxoid }\end{array}$ & $\begin{array}{l}\text { Microencapsulation of } \\
\text { sensitive compounds and } \\
\text { water-soluble (proteins, } \\
\text { peptides, vaccines) }\end{array}$ & $\begin{array}{l}\text { Polylactic acid (PLA, and poly(lactic-co- } \\
\text { glycolic) acid (PLGA) }\end{array}$ & $\begin{array}{l}\text { W/O/W-double emulsion } \\
\text { technique }\end{array}$ \\
\hline $\begin{array}{l}\text { Recombinant hepatitis B } \\
\text { surface antigen Bromocriptine } \\
\text { Progesterone and } \\
\text { theophylline Recombinant } \\
\text { humane rythropoietin } \\
\text { (rhEPO) Recombinant human } \\
\text { growth hormone (rh-GH) }\end{array}$ & $\begin{array}{l}\text { To encapsulate sensitive } \\
\text { substances such as essential } \\
\text { oils,vitamins and fragrance }\end{array}$ & $\begin{array}{l}\text { Poly(L-lactic acid), PLGA Stearylamine } \\
\text { containing cationic microspheres }\end{array}$ & Spray drying \\
\hline $\begin{array}{l}\text { Allogenic and xenogenic } \\
\text { hepatocytes }\end{array}$ & $\begin{array}{l}\text { Microencapsulation and } \\
\text { transplantation }\end{array}$ & $\begin{array}{l}\text { AN-69 (copolymer of sodium methallyl } \\
\text { sulfonate and acrylonitrile) }\end{array}$ & Co-extrusion \\
\hline Felodipine (FLD) & $\begin{array}{l}\text { Improve the dissolution rate } \\
\text { of drugs }\end{array}$ & Poly-(ethylene glycol) PEG 4000 & Supercritical fluid expansion \\
\hline
\end{tabular}

\section{Techniques of microencapsulation with Chitosan}

Many techniques have been used to encapsulate drugs with chitosan such as ionotropic gelation, emulsion phase separation, cross-linking with anions, emulsion solvent diffusion and coacervation. ${ }^{4}$

\section{Emulsion cross-linking technique}

The formulation of polymeric microspheres and some microparticles based on emulsion method has recently become more useful. Hydrophobic biodegradable polymers, like (PLGA) poly (lactic-co-glycolic acid) are one of the most common groups used on emulsions oil-in-water $(\mathrm{O} / \mathrm{W})$ or water-in-oil-in-water $(\mathrm{W} / \mathrm{O} / \mathrm{W})$. Delivery system preparations based in water-soluble polymer need the use of aqueous phase for dissolution of polymers. Consider chitosan as an example. It dissolved in a weak acid solution like acid acetic despite of its $\mathrm{pH}$-dependant solubility. Figure 4 shows the process of emulsion cross linking using suitable surfactants as emulsion stabilizers as well as the aqueous phase including the drug, is dispersed in an oil phase like oil of paraffin. ${ }^{19}$ On the other hand, the contact between proteins and water-oil interfaces caused deterioration because of the interfacial tension and the close levels of energy

barriers at the emulsion interfaces droplet. To protect proteins during the preparation of emulsion some approaches are available to stabilize it against any damage of structure. The use of chitosan as a hydrophilic water-soluble polymer reduces the free energy of hydrophilic proteins. This employment need to know more about the type of hydrophilic matrices which are used in this preparation. It has been demonstrated that the type of cross-linking agent influenced the release rate. The final microspheres particles size can be affected by many factors such as speed of stirring, cross-linking extent, and droplets size. ${ }^{21}$ Recent study suggested a method which based on extrusion under pressure with aqueous solution of chitosan. This manufacturing method used a membrane with systematic pores which incorporate inside a mixture of paraffin-petroleum ether. The final droplets dispersion of chitosan was uniform in size and cross-linked with glutaraldehyde. Tripolyphosphate (TPP) used to dissolve the peptidic drug in the chitosan solution and added the glutaraldehyde as a stabilizer. Using soaking process bovine serum albumin (BSA) was adsorbed in this case. By the same taken the membrane was emulsified with crosslinking process including tripolyphosphate (TPP) and glutaraldehyde as a stabilizer. The use of TPP prevent dehydration while the crosslinking step took place by glutaraldehyde. ${ }^{22}$ 


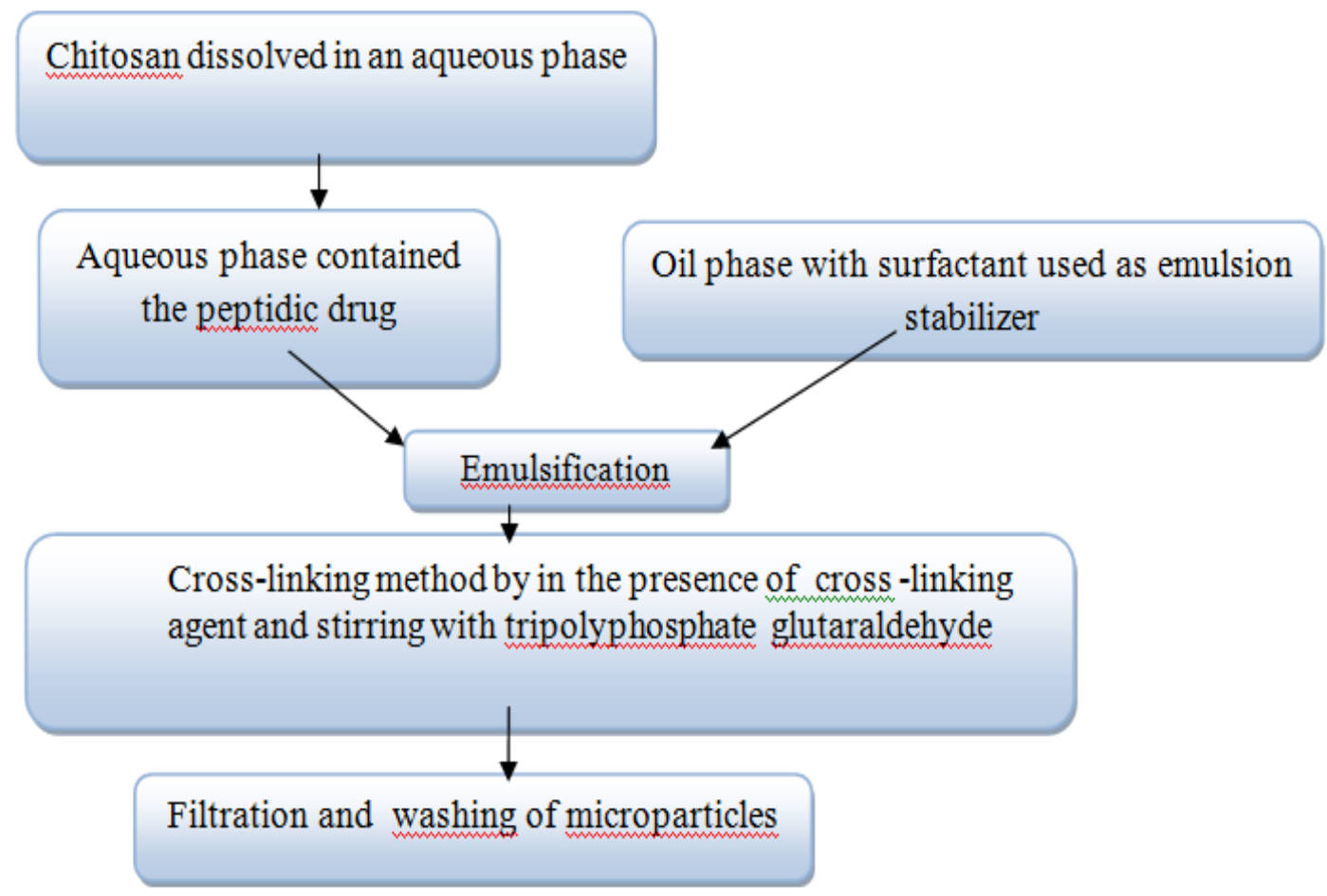

Figure 4 Emulsion cross-linking method. ${ }^{20}$

\section{Drying techniques}

These techniques include spray drying and supercritical fluid drying.

\section{Spray drying}

This process is the most commonly drying method used to prepare microparticles based on chitosan and chitosan derivatives. After the dissolution of chitosan in an aqueous medium the drug is dispersed in this solution. Tripolyphosphate solvent used to overcome the problem of poor solubility of non-cross-linked chitosan in aqueous media. The addition of natural cross-linking agents improves biocompatibility and performance of drugs. Hence, free-flowing particles can be produced after the solvent evaporation and atomization of small droplets. ${ }^{23}$ To obtain the suitable particle size many parameters should be controlled, such as extent of cross-linking, atomization pressure, the spray flow rate, size of the nozzle, and inlet air temperature. The use of adequate excipient reduces the risk of thermal degradation during the spray drying process. Polysorbate 20 can be used as protective agent of proteins from denaturation due to high shear rates during atomization step ${ }^{24}$ Previously, bovine serum albumin (BSA) was loaded as a protein type in microparticles using spray drying process. The characterization of physicochemical properties and integrity of protein encapsulated was made by circular dichroism and sodium dodecyl sulphate-polyacrylamide gel electrophoresis. The incorporation of BSA at high loading levels retained the integrity of protein entrapped. In consequence, the use of spray drying process to prepare chitosan microparticles including proteins has a good efficiency. For nasal delivery of vaccines, BSA also was encapsulated in chitosan microspheres in order to induce Immunoglobulin $G$ $(\mathrm{IgG})$ as an antigen-specific. These microspheres is then loaded with cetylpyridinium chloride used as an anti infective agent, followed by the addition of cross-linking agent. ${ }^{25}$ In terms of nanosystem applications by spray drying, chitosan nanoparticle loaded mannitol microspheres in order to transport therapeutic protein drug to the lungs. Nanoparticles were cross-linked with trypolyphosphate and loaded with BSA using ionic gelation process. The suspension result was spray-dried to produce dry powders of BSA-chitosanTPP nanoparticles. The characterization of the dispersion chitosan nanoparticles and mannitol in microspheres was made using timeof-flight secondary ion mass spectroscopy, X-ray photoelectron spectroscopy, and confocal laser scanning microscopy (CLSM). Mannitol used as a stabilizer of protein structure enhanced the aerosolization of protein drugs into lungs. ${ }^{26}$

\section{Supercritical fluid drying}

Usually, supercritical fluid process with carbon dioxide $\left(\mathrm{CO}_{2}\right)$ used to prepare diverse pharmaceutical applications despite of the low pressure and temperature. The process is nontoxic, nonflammable, and ensures the minimal decomposition of drugs like proteins. It provides also the possibility to prepare microparticles especially which are oriented for inhalation. As an example of loading drug or biopharmaceuticals into chitosan or chitosan derivatives, N-trimethylchitosan (TMC) microparticles were produced by spray drying process using the solution of albumin polymer including water, dimethyl sulfoxide DMSO, and supercritical $\mathrm{CO}_{2}\left(\mathrm{SC}-\mathrm{CO}_{2}\right)$ as an antisolvent. 
After that, DMSO water solution was added to the mixture in order to dissolve albumin and TMC. Thus they obtained spherical non agglomerated microspheres suitable for inhalation. ${ }^{27}$

\section{Ionic cross-linking method}

Ionic cross-linking are one of the most widely used methods for the preparation of chitosan microparticles. It have been extensively used for loading biopharmaceuticals. Moreover, this method does not support the use of organic solvent especially solvents with high temperatures. The ionic interactions between anionic charged of molecules and the positively charged of chitosan amino groups has a pivotal role in the formation of microparticles. Two main groups have been used as anionic cross-linkers: anionic low-MW molecules, like cyclodextrin derivatives or TPP; and anionic macromolecules, such as poly-y-glutamic acid, dextran sulfate, hyaluronic acid, and sodium alginate. ${ }^{20}$

\section{Coacervation and precipitation method}

This process is particularly useful to study the insolubility of chitosan in alkaline solution. Sodium hydroxide used to blow chitosan solution in order to prepare particles as shown in Figure 6. Drops was synthesised using air nozzle and ethanediamine or sodium hydroxide solutions. Blowing chitosan solution is one of the most common procedures for preparing drops. Recombinant interleukin-2 (rIL2) encapsulated into microparticles using sodium sulfate and acidic chitosan. Microparticles separation was carried out by centrifugation and freeze dried. The loaded process was made by adding protein to sodium sulfate. The control of chitosan concentration, protein amount and volume of sodium sulphate solution were carried out in this study. As a result, the encapsulated amount of rIL-2 was increased when the protein amount increased Figure $5 .{ }^{28}$

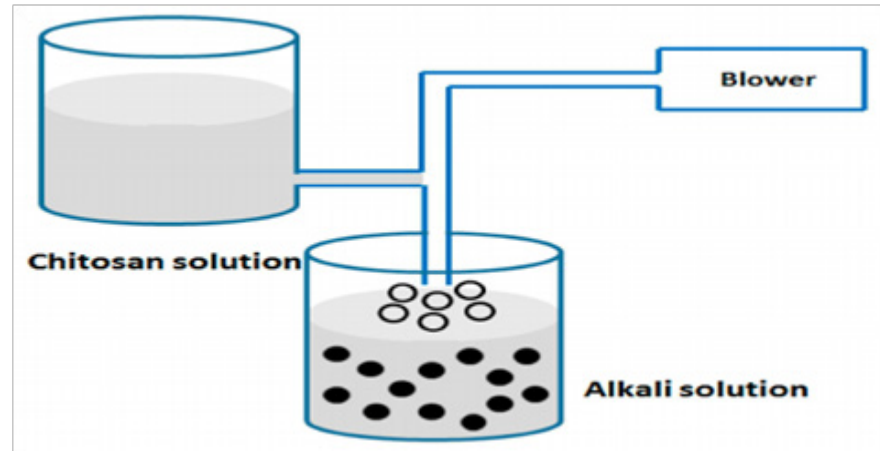

Figure 5 Process of coacervation and precipitation. ${ }^{20}$

\section{Ionotropic gelation method}

This process is one of the most common procedures for preparing chitosan nanoparticles using tripolyphosphate as a crosslinking agent as shows in Figure 6. A major advantage of this method was related to its mild conditions attained. It was selected for its reliability and validity for sensitive proteins without using harmful organic solvent and heat or agitation vigorous. Therefore, it has the ability to retain bioactive molecules such as proteins, DNA, etc. it has been established that chitosan nanoparticles have a good efficacy to associate with proteins. More recent attention has focused on the use of chitosan naoparticles to deliver polypeptides such as diphtheria and tetanus toxoid. ${ }^{29}$ In previous research, chitosan microparticles were formulated by ionotropic gelation and emulsification modified using tripolyphosphate, calcium and citrate as anions. As a result, an electrostatic interaction between chitosan and anions was carried out by various solutions. Among these approaches, various formulations of nanoparticles based on chitosan and Arabic gum were prepared using ionic gelation method for oral delivery of insulin. The solubility of chitosan and the $\mathrm{pH}$ values influenced the release of insulin. Hence, the diffusion of polymer affect the release controlled released of protein. $^{29}$

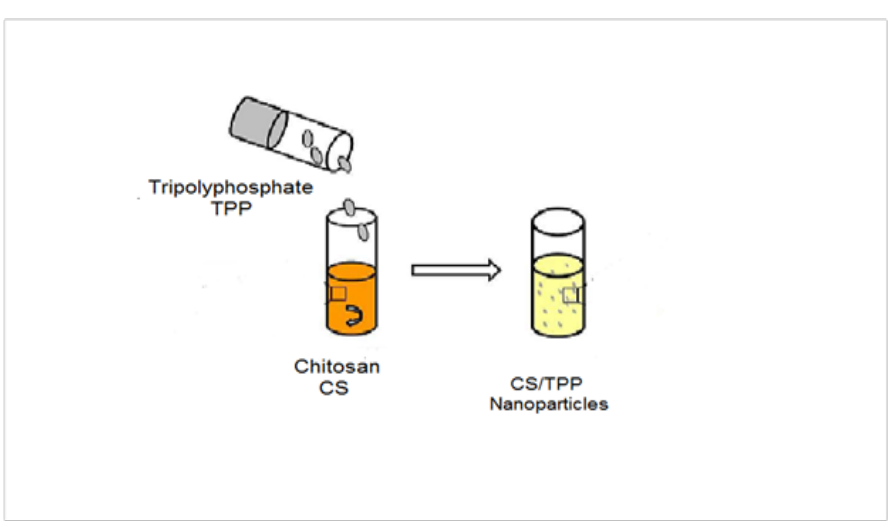

Figure 6 Representation of ionic gelation method. ${ }^{26}$

\section{Emulsion solvent diffusion}

Recently, the use of biodegradable polymers in microparticles and nanoparticles has increased in spite of their adequate properties and potential pharmaceutical applications. Numerous of processes have been reported for the preparation of nanoparticles drug delivery systems. Therefore, the efficacy of simple emulsion process remains to be identified. It may expect that emulsification solvent diffusion could be considered as a suitable process to formulate chitosan-based micro- and nanoparticles. Ethyl acetate and chitosan solution were used to prepare water-in-oil emulsion using Gentamicin sulfate as encapsulated drug. Chitosan was used as a coated material as well as Tripolyphosphate was added as a cross-inker agent. The result obtained did not mention any influence of the cross liker agent on shape and size of microparticles. The most important relevant finding was the decrease of drug release rates as well as the increase of cross linker amount. ${ }^{30}$ There are relatively few studies in the process of emulsion solvent diffusion. This method was developed to prepare poly (lacticco-glycolic) acid PLGA nanoparticles. The partial miscibility of the organic solvent is a common condition which has a considerable impact on the procedure. There is a growing body of literature that recognizes the importance of this process in pharmaceutical applications based on chitosan. The process-based on the addition of hydrophobic drug dissolved in an organic solvent to an aqueous phase contained chitosan using stabilizer ingredient like lecithin. As a result, the simple water-in-oil $\mathrm{O} / \mathrm{W}$ emulsion was formed upon high-pressure homogenisation. The addition of acetone decreased the solubility of chitosan. Hence, the isolation of nanoparticles was made using centrifugation process Figure $7 .{ }^{26}$ 


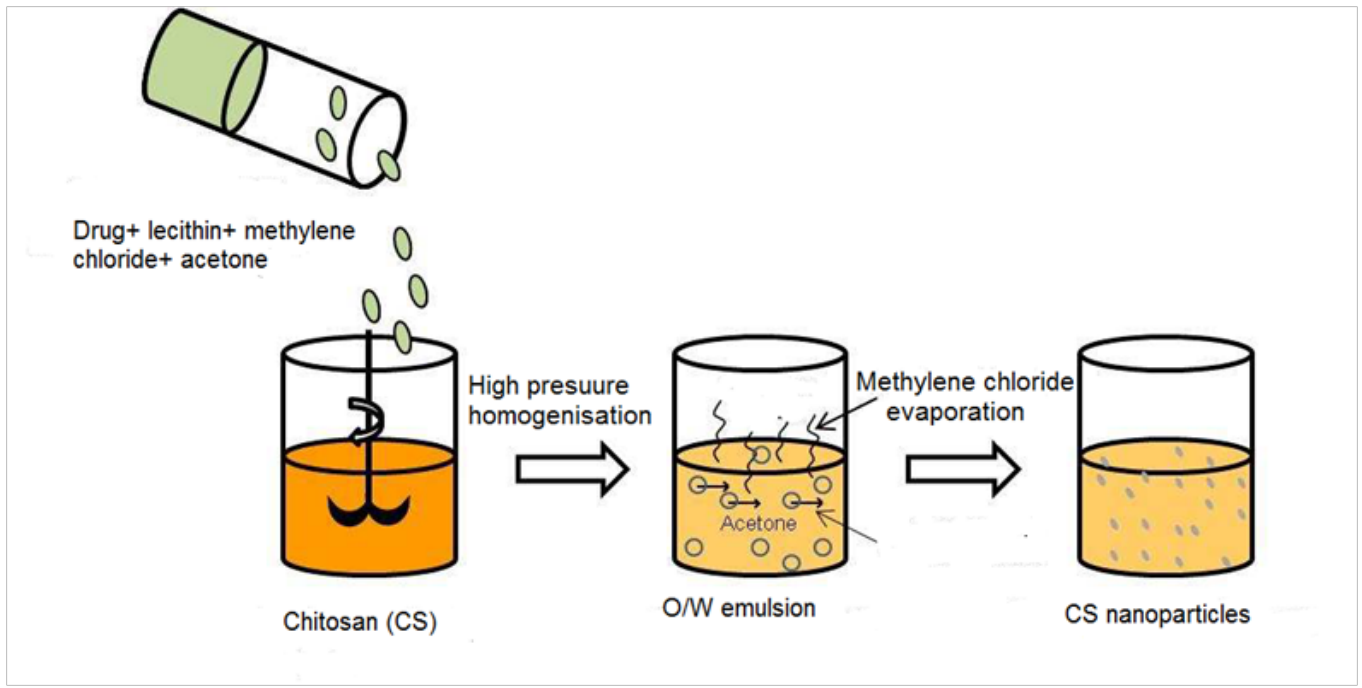

Figure 7 Representation of emulsion solvent diffusion. ${ }^{26}$

\section{Conclusion}

Various methods have been developed to improve the microencapsulation of chitosan in drug delivery carriers. Despite of its attraction properties, chitosan facilitated the delivery of many drugs into targets and specific sites. Therefore, such problems related to unavoidable fluctuations properties of biopolymers can reduce its uses to encapsulate drugs. Charge and size properties have a large effect on the capacity of drug encapsulation and targeting ability of these processes. However, many factors influence the drug loading, stabilizer, crosslinkig and release performance of chitosan-based micro- and nanoparticles. The materials composing matrix and preparation method have a greater impact on the microencapsulation process. In addition, the molecular weight and deacetylation degree of chitosan have also a great concern. In this review, there are a number of important differences between the existing methods. Thus, it was impractical to compare between several processes and conclude on those using chitosan as coating material for suitable pharmaceutical applications. Some of the available techniques are reported in a few researches in spite of their limit applications. Hence, numerous factors influenced the characteristics of final drug carrier have not been thoroughly studied in this work. On the other hand, the common technique that uses very mild conditions including hydrophilic medium is the ionic gelation process. In fact, many researchers have been widely used the process of ionic gelation in the application of chitosan drug carriers to produce strength forms of pharmaceutical formulations in order to achieve drug targets and improve the efficacy of treatment.

\section{Acknowledgements}

The authors duly acknowledge the support from University Putra Malaysia, The laboratory of Biochemical engineering, Department of Chemical and Environmental Engineering.

\section{Conflict of interest}

Author declares that there is no conflict of interest.

\section{References}

1. Kumar MN. A review of chitin and chitosan applications q. Reactive \& Functional Polymers. 2000;46:1-27.

2. Berta NE, Fernando R, Lucia S, et al. Microencapsulation with chitosan by spray drying for industry applications A review. Trends Food Sc Technol. 2013;31:138-155.

3. Wischke C, Schwendeman SP. Principles of encapsulating hydrophobic drugs in PLA / PLGA microparticles. Int J Pharm. 2008;364(2):298-327.

4. Suheylas K. Chitosan: properties, preparations and application to microparticulate systems. J Microencapsul. 1997;14(6):689-711.

5. Catherine T, Shyamali S, Meenakshi M, et al. Microencapsulation for the therapeutic Delivery of Drugs, live Mammalian and Bacterial Cells and Other Biopharmaceutics: Current Status and Future Directions. Journal of Pharmaceutics. 2013;2013:1-19.

6. Gupta A, Dey BK. Microencapsulation for controlled drug delivery : a comprehensive review. Sunsari Technical College Journal. 2012;1(1):48-54.

7. Bansode SS, Banarjee S, Gaikwad DD, et al. Microencapsulation : a review. Vishal Institute of Pharmaceutical Education and Research. 2010;1(2):38-43.

8. Ahlafi H, Moussout H, Boukhlifi F, et al. Kinetics of N-Deacetylation of Chitin Extracted from Shrimp Shells Collected from Coastal Area of Morocco. Mediterranean Journal of Chemistry. 2013;2(3):503-513.

9. Lim C, Woog D, Israelachvili J N, et al. Contact time- and pH-dependent adhesion and cohesion of low molecular weight chitosan coated surfaces. Carbohydrate Polymers. 2015;117(6):887-894.

10. Rieux A, Duhem N, Je C. Chitosan and Chitosan Derivatives in Drug Delivery and Tissue Engineering. Advances in Polymer Science. 2011;244:19-44.

11. Lee D W, Lim C, Israelachvili JN, et al. Strong Adhesion and Cohesion of Chitosan in Aqueous Solutions. Langmuir. 2013;29(46):14222-14229.

12. Sadigh Eteghad S, Talebi M, Farhoudi M, et al. Effects of Levodopa loaded chitosan nanoparticles on cell viability and caspase-3 expression 
in PC12 neural like cells. Neurosciences. 2013;18(3):281-283.

13. Wu Q, Lin D, Yao S. Design of Chitosan and Its Water Soluble Derivatives-Based Drug Carriers with Polyelectrolyte Complexes. Mar Drugs. 2014;12(12):6236-6253.

14. Ahmed S, Ikram S. Chitosan Based Scaffolds and Their Applications in Wound Healing. Achievements in the Life Sciences. 2016;10(1):27-37.

15. Fujita M, Kinoshita M, Ishihara M, et al. Inhibition of Vascular Prosthetic Graft Infection Using a Photocrosslinkable Chitosan Hydrogel. J Surg Res. 2004;121(1):135-140.

16. Mitra A, Dey B. Chitosan Microspheres in Novel Drug Delivery Systems. Indian J Pharm Sci. 2011;73(4):355-366.

17. Dutta PK, Dutta J, Tripathi, VS. Chitin and chitosan : Chemistry, properties and applications. Journal of Scientific and Industrial Research. 2004;63:20-31.

18. Dubey R. Microencapsulation Technology and Applications. Defence Science Journal. 2009;59(1): 28-95.

19. Maculotti K, Tira EM, Sonaggere M, et al. In vitro evaluation of chondroitin sulphate-chitosan microspheres as carrier for the delivery of proteins. J Microencapsul. 2009;26(6):535-543.

20. Ferrari F, Bonferoni MC, Rossi S, et al. Manufacture Techniques of Chitosan-Based Microparticles and Nanoparticles for Biopharmaceuticals. John Wiley \& Sons. 2007;9:137-158.

21. Agnihotri N, Mishra R, Goda C, et al. Microencapsulation - A Novel Approach in Drug Delivery: A Review. Indo Global Journal of Pharmaceutical Sciences. 2012;2(1):1-20.
22. Wang LY, Gu YH, Su ZG, et al. Preparation and improvement of release behavior of chitosan microspheres containing insulin. Int $J$ Pharm. 2006;311(1-2):187-195.

23. Mi FL, Tan YC, Liang HF, et al. In vivo biocompatibility and degradability of a novel injectable-chitosan-based implant. Biomaterials. 2002;23(1):181-191.

24. Johnson KA. Preparation of peptide and protein powders for inhalation. Adv Drug Deliv Rev. 1997;26(1):3-1.

25. Alpar H, Somavarapu S, Atuah K, et al. Biodegradable mucoadhesive 5 particulates for nasal and pulmonary antigen and DNA delivery. Advanced Drug Deliv Rev. 2005;57(3):411-430.

26. Grenha A, Seijo B, Serra C. et al. Chitosan nanoparticle-loaded mannitol microspheres: structure and surface characterization. Biomacromolecules. 2007;8(7):2072-2079.

27. Okamoto H, Sakakura Y, Shiraki K., et al. Stability of chitosan - pDNA complex powder prepared by supercritical carbon dioxide process. Int $J$ Pharm. 2005;290(1-2):73-81.

28. Ozbas Turan S, Akbuga J, Aral C. Controlled release of interleukin-2 from chitosan microspheres. J Pharm Sci. 2002;91(5):1245-251.

29. Eskandari R, Avadi M, Zolfagharian H, et al. Preparation and in vitro characterization of chitosan nanoparticles containing Mesobuthus eupeus scorpion venom as an antigen delivery system. J Venom Anim Toxins incl Trop Dis. 2012;18:44-52.

30. Phromsopha T, Baimark Y. Chitosan microparticles prepared by the Water in Emulsion Solvent Diffusion Method for drug delivery.Biotechnologie. 2010;9(1):61-66. 